\title{
Efficacy of Kasturba Gandhi Balika Vidyalaya (KGBV) in Assam on academic performance of children
}

\author{
SAMPREETY GOGOI AND UTPALA GOSWAMI
}

Received: 25.02.2015; Revised: 12.04.2015; Accepted: 29.04.2015

See end of the paper for authors' affiliations UTPALA GOSWAMI

Directorate of Extension Education, Assam Agricultural University, JORHAT (ASSAM) INDIA
ABSTRACT : The teaching- learning needs of girls in the KGBV are a challenge as well as an opportunity. All KGBV girls have a break in their schooling due to family or other circumstances. Many of the girls have in the past been out of school or have dropped out of the school at some stage. Across the board they come from families and from villages which were educationally backward. It is therefore to be expected that such girls are likely to be lagging behind academically. The challenge should be developed into an opportunity as the KGBV is a residential programme for three years. In most of the cases there are adequate numbers of teachers, possibilities of flexible time and methods, and overall a high motivation from the girls and from their families for improved learning. It is therefore essential for the teachers, wardens and the programme officers to work out what methods and material should be used to accelerate their learning level more, and enable the girls to reach grade level knowledge and skills. To balance academic learning along with other issues three years is a long period. If the teacher wishes and put in more efforts and introduces innovative ways then they can create wonder in the academic achievement of the girls.

KEY WORDS: Efficacy, Kasturba Gandhi Balika Vidyalaya, Academic, Performance

- HOW TO CITE THIS PAPER : Gogoi, Sampreety and Goswami, Utpala (2015). Efficacy of Kasturba Gandhi Balika Vidyalaya (KGBV) in Assam on academic performance of children. Asian J. Home Sci., 10 (1) : 161-167. 